\author{
Marquette University \\ e-Publications@Marquette
}

College of Nursing Faculty Research and

Publications

Nursing, College of

$5-2008$

\title{
The Development of the NAPNAP Research Agenda: Priorities for Evidence in Pediatric Practice 2008-2013
}

\author{
Kathleen J. Sawin \\ University of Wisconsin - Milwaukee \\ Arlene Butz \\ The Johns Hopkins University \\ Margaret A. Brady \\ Azusa Pacific University \\ Agatha M. Gallo \\ University of Illinois at Chicago College of Nursing \\ Dolores Jones \\ National Association of Pediatric Nurse Practitioners
}

See next page for additional authors

Follow this and additional works at: https://epublications.marquette.edu/nursing_fac

Part of the Nursing Commons

\section{Recommended Citation}

Sawin, Kathleen J.; Butz, Arlene; Brady, Margaret A.; Gallo, Agatha M.; Jones, Dolores; Lewin, Linda C.; Niederhauser, Victoria P.; Schindler, Christine A.; and Trent, Cynthia A., "The Development of the NAPNAP Research Agenda: Priorities for Evidence in Pediatric Practice 2008-2013" (2008). College of Nursing Faculty Research and Publications. 700.

https://epublications.marquette.edu/nursing_fac/700 


\section{Authors}

Kathleen J. Sawin, Arlene Butz, Margaret A. Brady, Agatha M. Gallo, Dolores Jones, Linda C. Lewin, Victoria P. Niederhauser, Christine A. Schindler, and Cynthia A. Trent 
Marquette University

e-Publications@Marquette

\section{Nursing Faculty Research and Publications/College of Nursing}

This paper is NOT THE PUBLISHED VERSION; but the author's final, peer-reviewed manuscript. The published version may be accessed by following the link in the citation below.

Journal of Pediatric Health Care, Vol. 22, No. 3 (May/June 2008): 208-210. DOI. This article is (C) Elsevier and permission has been granted for this version to appear in e-Publications@Marquette. Elsevier does not grant permission for this article to be further copied/distributed or hosted elsewhere without the express permission from Elsevier.

\section{The Development of the NAPNAP Research Agenda: Priorities for Evidence in Pediatric Practice 2008-2013}

\section{Kathleen J. Sawin}

Professor and Research Chair, Nursing of Children, Children's Hospital of Wisconsin and the College of Nursing, University of Wisconsin-Milwaukee, Milwaukee, Wis

Arlene Butz

Professor, The Johns Hopkins University Schools of Medicine and Nursing Division of General Pediatrics, Baltimore, Md

Margaret A. Brady Professor, California State University Long Beach College of Health \& Human Services, Department of Nursing, Long Beach, Calif

Agatha M. Gallo

Professor, College of Nursing, University of Illinois at Chicago, Chicago, Ill

Dolores Jones 
Director of Practice, Education, and Research, National Association of Pediatric Nurse Practitioners, Cherry Hill, NJ

\section{Linda C. Lewin}

Assistant Professor, Frances Payne Bolton School of Nursing, Case Western Reserve University, Cleveland, Ohio

\section{Victoria P. Niederhauser}

Associate Professor and Department Chair, School of Nursing \& Dental Hygiene, University of Hawaii, Honolulu, Hawaii

\section{Christine A. Schindler}

Pediatric Nurse Practitioner, Children's Hospital of Wisconsin and Division of Critical Care, Medical College of Wisconsin, Milwaukee, Wis

\section{Cynthia A. Trent}

Certified Pediatric Nurse Practitioner, Laurelwood Pediatrics, Memphis, Tenn

The mission of the National Association of Pediatric Nurse Practitioners (NAPNAP) is to promote optimal health for children through leadership, practice, advocacy, education, and research. "Children" in this article refers to infants, children, adolescents, young adults, and their families. Central to this mission is delineating the evidence for practice. To this end, NAPNAP's current strategic plan includes developing its first Research Agenda. NAPNAP's goal in developing this Research Agenda is to identify gaps in evidence for practice, thus providing direction for research activities to NAPNAP, as well as other organizations, and to facilitate the work of interdisciplanary groups and individual scientists who can address these gaps. The Research Agenda was developed to address gaps in evidence for practice of members who are primarily pediatric nurse practitioners, family nurse practitioners, school nurses, clinical nurse specialists, educators, and/or researchers. Members' area of clinical focus is either primary care (including school health, child care, and other community-focused settings), acute care (caring for children in acute and critical care settings), or specialty care (caring for children with chronic health conditions delineated in federal programs as children with special health care needs in both primary and acute care settings). This agenda informs the membership and nurse scientists regarding NAPNAP's child health research priorities. The agenda also can give direction to NAPNAP's multiple organizational constituents such as the NAPNAP Executive Board, regional chapters, and affiliated groups (e.g., the NAPNAP Foundation and the Association of Faculties of Pediatric Nurse Practitioners) for prioritizing research-related activities.

The Research Agenda was developed using multiple procedures, including the nomination of research priorities by NAPNAP's Six Special Interest Groups and the Association of Faculties of Pediatric Nurse Practitioners members, data collection from three focus groups held at the 2007 NAPNAP National Conference, and the implementation of an online survey for members to rate the nominated research priorities. The three focus groups included NAPNAP members who identified having either a primary, acute or specialty practice focus. The NAPNAP Research Agenda Work Group synthesized the potential priorities from the first two activities into an Institutional Review Board-approved online survey for 
member ranking and feedback. Three hundred twenty-five members participated in the online ranking process, and 293 identified their area of practice, with 168 participants (57.3\%) of those indicating the area of practice as primary care, $45(15.4 \%)$ as acute care, $80(27.3 \%)$ as specialty care. In an intensive 2-day meeting, the Work Group analyzed members' ranking of priorities and the issues for investigation that emerged from the survey process and generated a Research Agenda with six clinical and three professional components (see the Box).

\section{The NAPNAP research agenda: focus areas for research in pediatric practice \\ Clinical}

\section{Health Promotion/Disease Prevention}

It is important to enhance the body of evidence on health promotion/disease prevention outcomes for optimal child and family health across all ethnic/racial, highrisk, and socioeconomic groups. The linkage between lifestyle behaviors, genetics, and health outcomes is well documented; however, adoption and adherence to these practices continue to be a challenge for many families and children. Important issues include developing and testing new screening strategies, measuring outcomes related to education and anticipatory guidance, and studying interventions to enhance adoption of and adherence to health promotion/disease prevention practices.

\section{Self-management of Acute and Chronic Conditions}

Effective self-management of acute and chronic health care conditions can result in decreased symptoms and limitation of activity, prevention of further disease progression, and improved quality of life. Self-management skills for children and their families can be enhanced by effective interventions that address parent/child knowledge, their attitudes, and beliefs regarding the health condition. Testing effective self-management strategies that are family-child centered and investigating the facilitators of and barriers interfering with adherence to health care recommendations are imperative. Exploring the impact of the use of community resources and complementary therapies also are warranted. Self-management skills, in both inpatient and outpatient settings, that address developmental issues and transitions from adolescence to adulthood should be explored.

\section{Mental Health for Children and Families}

Optimal mental health in individuals, families, and communities is a central goal of Pediatric Nurse Practitioner (PNP)/Advance Practice Nurse (APN) practice. Mental health issues include the domains of prevention, screening, early detection of problems, and treatment of mental illness. Included in these areas are priorities that address antecedents to mental health problems and strategies that prevent disruptions in mental health. Additionally, priorities that address youth with risk factors or complicated family situations such as adapting to foster care, special needs children, military deployment or re-integration, homelessness, incarcerated or impaired parents, or infants born at risk need to be considered. 
IV. Safety: Protecting Child from Disease, Infection, and Harm

The provision of care that optimizes child/family safety in the home, school, community, and health care settings is paramount in pediatric health care. Research in this category may address (a) safety directly (e.g., childhood accidents, injuries, infections, maltreatment, or violence), (b) the environmental or system issues that affect safety of care delivered in pediatric settings, or (c) the effective assessment and management of common childhood conditions.

V. Children/Families Dealing with Acute/Critical Health Issues

In addition to providing primary care, PNPs/APNs are assuming expanding roles in acute/critical care settings. The clinical practice issues confronted in these settings include implementing optimal family-centered care, enhancing child/family coping strategies to deal with difficult situations, enhancing comfort and decreasing pain, and providing care that optimizes physiological function.

VI. Obesity

The increasing incidence of childhood overweight and obesity across the life span requires a greater understanding of multiple risks factors associated with obesity and evaluation of interventions to prevent or treat obesity. Effective strategies to reduce the burden of childhood and adolescent obesity across all racial, ethnic, and socioeconomic groups need to be explored. Studying the impact of obesity on the management of children with chronic and acute conditions also requires further investigation.

Professional/System

\section{Role/Practice Issues/Factors Related to PNP/APN Practice}

The PNP/APN roles have evolved dramatically during the past 30 years. PNPs/APNs now provide a variety of health care services to children and families including primary care, chronic and specialty care management, emergency department care, and management of the hospitalized child. Changes in the role and scope of PNP/APN practice require both continuing and new directions in research inquiry to document quality of care issues, to obtain productivity data for APNs, to investigate the impact of emerging technologies, and to identify barriers to effective role implementation.

\section{Organizational/Systems/Environmental Issues}

Organizational/systems/environmental factors can affect APN practice, role, and outcomes. Research addressing these environments of care is important to delineate how and under what conditions these factors influence health care.

\section{Quality of PNP/CNS/APN Care}

PNPS/APNs working in pediatrics provide health care in a variety of child health areas and settings. Research that delineates the processes and outcomes of care is important to determine quality.

The final NAPNAP Research Agenda delineates both the clinical and professional components and provides exemplar priorities in each focus area. Efforts were made to reflect the top priorities of each practice focus area. The document was posted on the NAPNAP Web site for public comment from April 
1-30, 2008. The Research Agenda Work Group, NAPNAP's Research Committee, and the Chair of the Foundation's Research Committee will review all public comment, make revisions, and present to the Research Agenda to NAPNAP's Executive Board for final approval in June 2008.

It is expected that the NAPNAP member-focused Research Agenda will be utilized in several ways. Clinicians can further generate questions in the research areas and policy makers can promote initiatives and projects to address the evidenced-based gaps identified in the agenda. In addition, pediatric researchers in primary, acute, and specialty care can use the Research Agenda to guide the focus and development of their research activities. Ultimately, the new Research Agenda will inform private and federal decisions for child health funding initiatives and stimulate new evidence for practice. NAPNAP's Research Agenda will improve pediatric health care and advance the growth of advanced nursing practice. The complete NAPNAP Research Agenda: Priorities for Evidence in Pediatric Practice 2008-2013 with exemplars for each of the focus areas can be found on the NAPNAP Web site (www.napnap.org) after July 1, 2008. 